\title{
Material-Associated Bone Resorption
}

DOI: $10.17691 / \mathrm{stm} 2018.10 .4 .03$

Received May 12,2018

A.P. Bonartsev, PhD, Leading Researcher, Department of Bioengineering ${ }^{1}$; Researcher, Laboratory

of Microorganism Nitrogen Fixation, Bach Institute of Biochemistry of the Russian Academy of Sciences2;

A.A. Muraev, MD, PhD, Associate Professor, Department of Maxillofacial Surgery and Surgical Dentistry3;

R.V. Deyev, MD, PhD, Head of the Department of Histology, Pathologic Anatomy, and Medical Genetics4;

A.V. Volkov, MD, PhD, Associate Professor, Department of Pathologic Anatomy33; Senior Researcher,

Laboratory for Studies of the Connective Tissue ${ }^{5}$

Lomonosov Moscow State University, 1/12 Leninskie Gory, Moscow, 119991, Russia;

2Federal Research Center "Fundamentals of Biotechnology" of the Russian Academy of Sciences,

33/2 Leninskiy Prospect, Moscow, 119071, Russia;

${ }^{3}$ Peoples' Friendship University of Russia, 6 Miklukho-Maklaya St., Moscow, 117198, Russia;

4.P. Pavlov Ryazan State Medical University, 9 Vysokovoltnaya St., Ryazan, 390026, Russia;

${ }^{5}$ N.N. Priorov National Medical Research Center of Traumatology and Orthopaedics,

Healthcare Ministry of Russia, 10 Priorov St., Moscow, 127299, Russia

A number of similar macrophage responses to the implantation of various osteoplastic materials into bone defects in humans and laboratory animals have been demonstrated in the present article based on the retrospective analysis of the archival histological material (2008-2016). The presence of osteoplastic materials in a bone regenerate has led to the emergence of giant cells of foreign bodies and osteoclastogenic cells both on the surface of the material and neoformed bone with its subsequent resorption. It was suggested to name this phenomenon "material-associated bone resorption".

Key words: regenerative medicine; tissue engineering; bone tissue; giant cells of foreign bodies; osteoclasts; osteoplastic materials; bone resorption.

\section{Introduction}

At present, more and more attention is paid to the study of the role of the giant multinucleated cells in the interrelation of the organism and osteoplastic material introduced separately [1] or incorporated into tissueengineered constructs [2]. Materials for targeted bone regeneration generally meet safety requirements, however, being foreign bodies by their nature, they are able to evoke giant cell reactions [3, 4]. As a consequence, the development of the inflammatory reaction to the introduced material is the specificity of the regenerative process $[5,6]$. In some cases, biodegradation of the material promotes the release of the active factors stimulating bone regeneration $[6,7]$. The present notion about the cells of the macrophagal differon (differentiation pathway, programmed differentiation) involved in the process of regeneration and remodeling of the bone matrix has been formulated in classic works and is not subjected to serious revision [8]. Currently, M1 cells are referred to those modeling the collagen matrix, while M2 cells to the cells of foreign bodies which are activated in case of the foreign body presence [9].

The specificity of giant cell reactions in bone tissue lies in the fact that in response to the osteoplastic material implantation in a multitissue regenerate the cells of different branches of divergent differentiation within the monocytic differon - giant multinucleated cells of foreign bodies and/or true osteoclasts - may be generated. To gain an insight into the nature of the giant multinucleated cells is not only of academic interest but the concept has an important prognostic value for further regeneration process running in the orthotopic bone bed. Thus, the metabolic activity of giant multinucleated cells as the main effectors of granulomatous reactions results in the appropriate activation of fibroblastic differon cells and progressive development of the connective tissue component in the bone regeneration area which contradicts to the concept of the osteoplastic material efficiency being the basis of its creation. Osteoclasts are important components of the bone tissue and through the mechanisms of cytokine activity regulation of the basic multicellular units may serve as early predictors of full osteoplastic material resorption and concurrent and subsequent synthesis of the bone substance by osteoblasts.

Our observations of the processes of osteogenesis and bone regenerate remodeling in cases of implanted osteoplastic materials made us pay attention to such

Corresponding author: Aleksey V. Volkov, e-mail: alex.volkoff@gmail.com 
properties of osteoclasts and giant cells of foreign bodies which previously were neglected by investigators and do not quite fit in the traditional concept of dividing the cells of macrophage lineage into functional classes [3, 9].

\section{Materials and Methods}

Objects of investigation. For our study, we used specimens of human and animal bone regenerates after the implantation of commercial and unregistered osteopathic materials based on calcium phosphate of the natural and artificial origin, osteoplastic materials from lyophilized bone tissue stored in the archive of the Laboratory for Studies of the Connective Tissue of N.N. Priorov National Medical Research Center of Traumatology and Orthopaedics (the period of observations covered 2008 to 2016) [7, 9-11].

Implantation of commercial osteoplastic materials to a man was performed during tooth extraction to compensate the bone tissue volume within the research programs carried out at the Central Research Institute of Dentistry and Maxillofacial Surgery and at the Department of Maxillofacial Surgery and Surgical Dentistry of Peoples' Friendship University of Russia. Within the scope of the current work, examination of the bone regenerates (trepanobioptates) was done 6 months after the implantation of the following materials: Bio-Oss and Bio-Oss Collagen (Geistlich Biomaterials, Switzerland), Osteoplast-M (Vitaform, Russia), Osteodent (Rusimplant, Russia) as well as a tissue-engineered construct based on adiposetissue-derived multipotent mesenchymal stromal sells predifferentiated in the osteogenic direction (ReMeTex, Russia). Before dental implant installation, bone tissue specimens were harvested from 85 patients (a total of 102 trepanobiopsies) which were later histologically examined. The study complies with the Declaration of Helsinki (2013) and was performed following the approval by the Ethics Committee of Peoples' Friendship University of Russia. Written informed consent was obtained from every patient.

Implantation of unregistered osteoplastic materials (poly(3-hydroxybutyrate)), octacalcium phosphate was carried out within the scope of research works at the Department of Bioengineering of the Biological Faculty of Lomonosov Moscow State University poly(3hydroxybutyrate)-based material was obtained by a microbiological method [12]) and experiments with the introduction of octacalcium phosphate (Histograft, Human Stem Cells Institute, Russia) in the critical defects of rabbit temporal bones, rat femoral bones, and within the framework of preclinical studies.

Histological examination. The specimens were fixed in neutral 10\% formalin (Bio-Vitrum, Russia), subjected to a standard histological preparation, and embedded into paraffin (BioVitrum, Russia). Semi-serial sections were cut from the blocks with staining of every third section. To detect specific phenomena in the bone tissues, we used not only staining with hematoxylin and eosin but Masson-Goldner and Papanikolaou staining as well which, owing to stain metachromasy, revealed cellular elements of the macrophage lineage along with the bone structures of different maturity degree. Photodocumenting was performed using Leica DM 2500 microscope and EC3 digital camera (Leica Microsystems, Germany).

\section{Results}

When analyzing the interrelations of implanted materials with the recipient orthotopic bed tissues it has been established that all materials evoke, in a varying degree, the response of chronic inflammatory reaction type to a foreign body but in contrast to the classic chronic inflammation, the signs of forming the capsule around the material are absent in some cases [13]. Let us consider some specific aspects of material-associated bone resorption (MABR) manifestation on the surface of the osteoplastic material and neoformed bone.

MABR on the granule surface of the osteoplastic material Bio-Oss and Bio-Oss Collagen (natural origin, treated xenogenic bone). At implantation, cellular elements of the macrophagal lineage resembling osteoclasts (osteoclastoid cells) resorbing this material are detected. Material resorption is seen on the surface free from bone deposits. If deposits of osteoid or mineralized bone matrix are present on the material surface, scalloped resorption of the bone matrix occurs first, and then the process continues on the material surface. Bone matrix resorption is accompanied by dropping the osteocyte out of the lacuna to the medullary space. Once the osteoclatoid cell reached the implanted material, resorption goes on not into the depth of the material but rather over its surface involving more and more new areas of deposited reticulofibrous bone tissue regardless of the degree of its differentiation. But effective resorption does not occur. Osteoclastoid cells inducing the activity of osteoblasts via a paracrine mechanism are most likely to stimulate new deposits on the surface of the osteoid which is again subjected to resorption. The bone matrix formed on the granule surface does not have evident lines of agglutination (Figure 1).

$M A B R$ in response to the implantation of the osteoplastic materials based on the synthetic tricalcium phosphates and octacalcium phosphates. Resorption in this case has some principal differences. Giant cells of foreign bodies covering the material granules and sometimes penetrating into their pores are found on the osteoplastic material surface. Osteoinductive and osteoconductive properties of the material promote its deposition and maturation on the bone matrix surface. The giant cells of foreign body, in their turn, are disposed on the granule surface free of the bone and spread expansively over the material surface. When a neoformed bone is encountered, tunnels are 


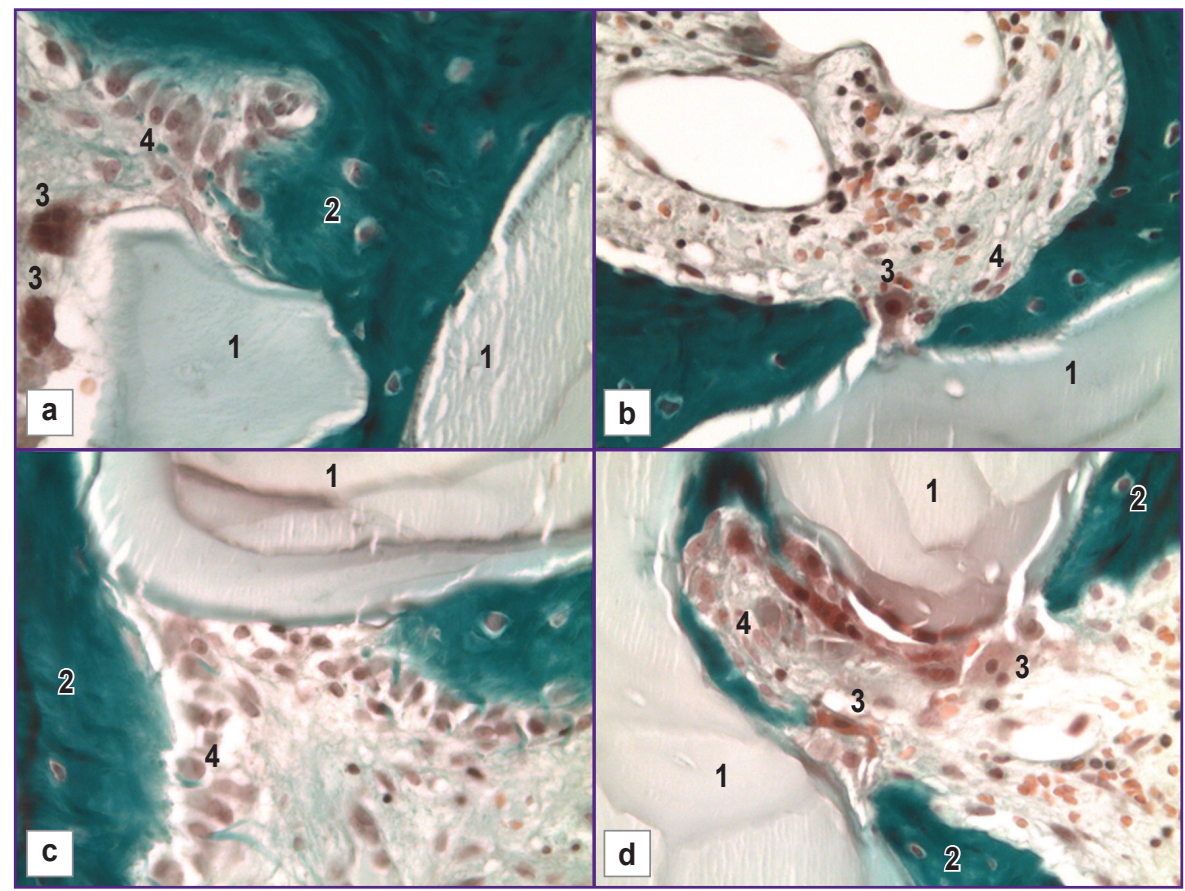

Figure 1. Histological picture of bone regenerate trepanobioptate 180 days after the implantation of Bio-Oss osteoplastic material:

(a) osteogenesis and osteoclastoid cells on the material granule surface; (b) tunnel resorption: the osteoclastoid cell after bone substance resorption reaches the material surface; (c) osteogenesis on the material granule surface; (d) parallelly running processes of osteogenesis and osteoclasia on the granule surface of the material; 1 - bone material; 2 a neoformed reticulofibrous bone tissue; 3 - osteoclastoid cells; 4 - activated osteoblasts; MassonGoldner staining; x400

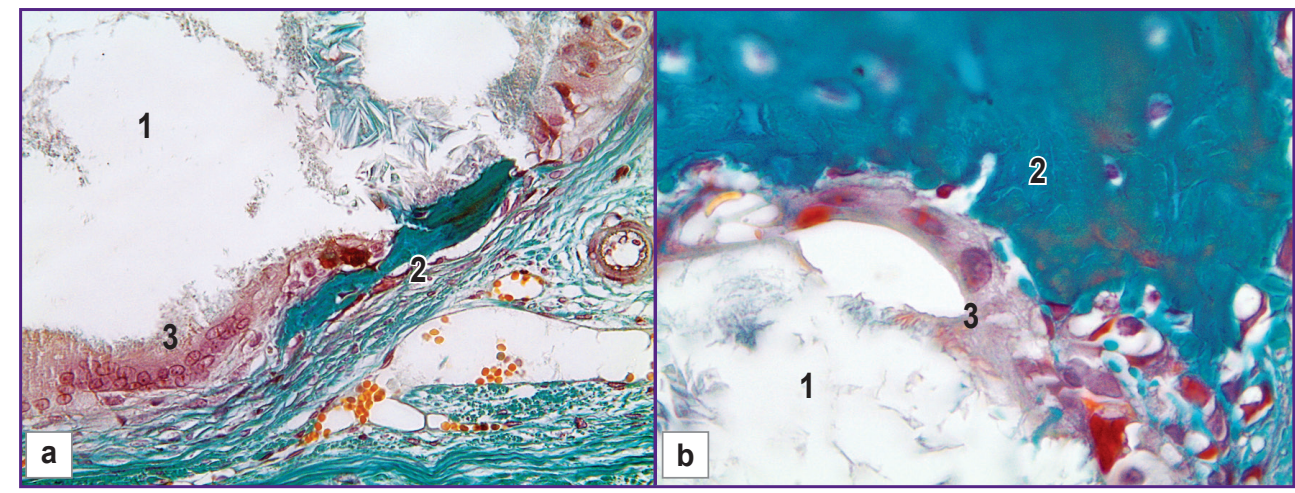

Figure 2. A fragment of the histological section of the bone regenerate of the rabbit parietal bone 60 days after tricalcium orthophosphate implantation:

(a) tunnel resorption of the osteoplastic material; $x 200$; (b) tunnel resorption: concurrent resorption of the giant cells of foreign body of the bone tissue and material; x1000; 1 - osteoplastic material; 2 - neoformed reticulofibrous bone tissue; 3 - giant cells of foreign body; Masson-Goldner staining

formed with the bone serving as an arch and the material as a base (Figure 2).

The giant cell resorption border is simultaneously found on the material and bone surface and droppingout of osteocytes from the lacunes occurs just in the same way as in osteoclastoid resorption of the natural mineral materials. The oxyphilic chromatin of the dropped-out osteocytes speaks of the apoptotic process in the osteocyte (Figure 3).

Having defined the characteristic signs of bone tissue resorption after the implantation of osteoplastic materials of different origin, we continued studying other agents inducing and stimulating osteogenesis. For the analysis, we chose the tissue specimens obtained after the implantation of the demineralized bone matrix, transplantation of tissue-engineered constructs, and synthetic materials based on the organic acid polyesters.

MARB after the implantation of demineralized natural bone (purified bone collagen matrix). The described phenomenon is established to appear only in case of granulomatous productive inflammation emerging in response to the introduced material. If there were no signs of inflammation, bone resorption evidence was also not found (Figure 4).

MARB after the implantation of synthetic poly(3hydroxybutyrate)-based material. This material was introduced into the defect of the rat femoral bone. The neoformed and maturating bone tissue was found to be resorbed by the giant cells of foreign bodies (Figure 5).

MARB after the implantation of tissue-engineered 
Figure 3. A fragment of the histological section of the bone regenerate of the rabbit parietal bone 90 days after tricalcium orthophosphate implantation:

(a) concurrent resorption of the giant cells of foreign body of the bone tissue and material; x200; (b) a new cycle of resorption of the neoformed bone tissue on the material granule; x200; (c) dropping out of osteocytes into the lumen in tunnel resorption; $\mathrm{x} 1000$; (d) completion of material resorption; there is no bone tissue around the residual granule of the giant cells of foreign body; x200; 1 - osteoplastic material; 2 a neoformed reticulofibrous bone tissue; 3 - osteoclastoid cells; 4 - fibrous connective tissue; Papanikolaou staining
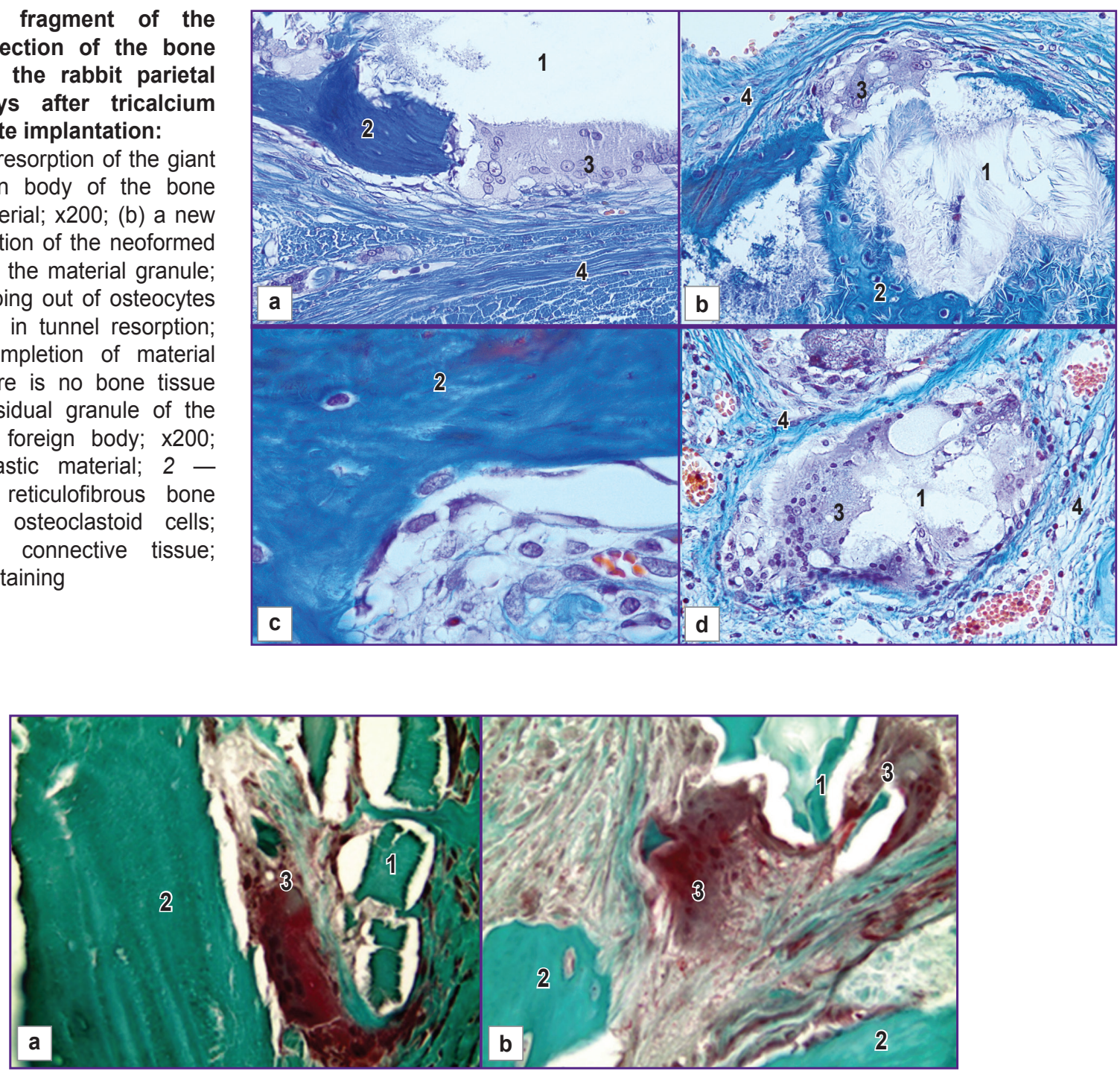

Figure 4. A histological section fragment of collagen-containing osteoplastic material trepanobioptate:

(a) the giant cells of foreign body are fragmenting the material granule being located on the surface of the neoformed bone tissue; $\mathrm{x} 200$; (b) concurrent resorption of the giant cells of foreign body of the bone tissue and material; $\mathrm{x} 400 ; 1-$ osteoplastic material; 2 - a neoformed reticulofibrous bone tissue; 3 - the giant cells of foreign body; Masson-Goldner staining

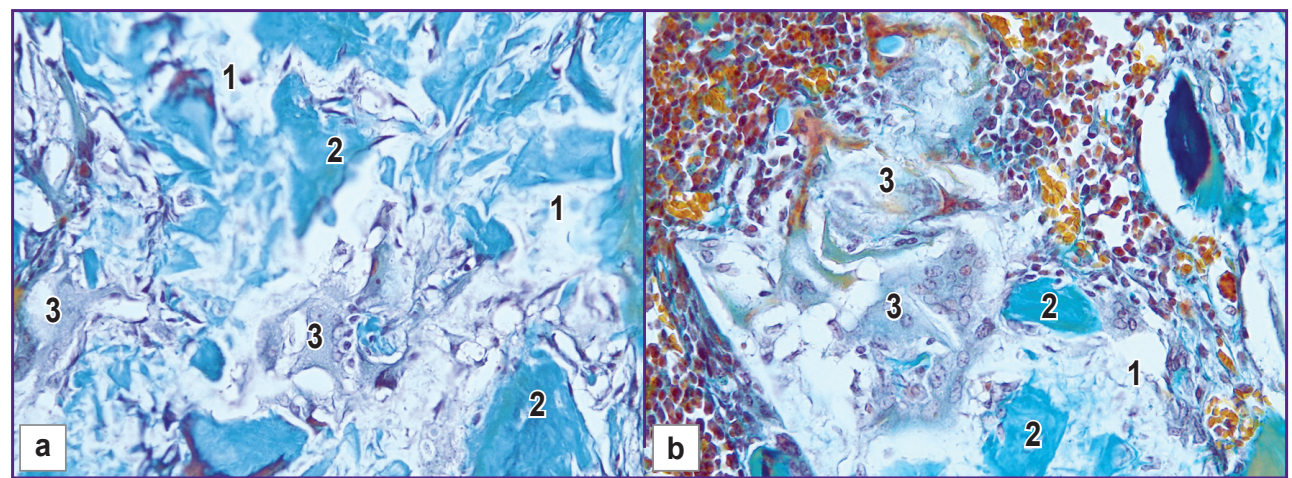

Figure 5. A histological section fragment of the rat femoral bone 28 days after poly(3-hydroxybutyrate) implantation into the bone marrow:

(a) parallel generation and resorption of the bone tissue by the giant cells of foreign body; $x 400$; (b) phagocytosis of the neoformed bone by the giant cells of foreign body from the material surface; $x 400 ; 1-$ osteoplastic material; 2 - a neoformed reticulofibrous bone tissue; 3 - giant cells of foreign body; Papanikolaou staining 


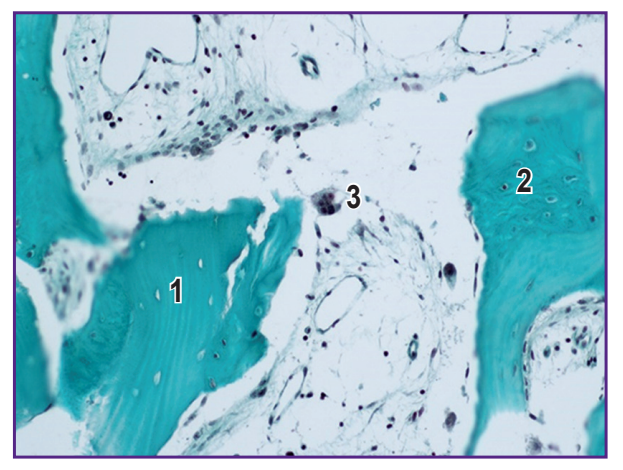

Figure 6. A histological section fragment of the bone regenerate trepanobioptate 120 days after tissueengineered construct transplantation

Osteoclastoid cell on the neoformed bone surface; signs of recent resorption of osteoblastic material; 1 - osteoplastic material; 2 - a neoformed reticulofibrous bone tissue; 3 giant cells of foreign body; Masson-Goldner staining; $x 400$

constructs based on autogenic multipotent mesenchymal stromal adipose tissue-derived cells. These constructs were predifferentiated in the osteogenic direction in combination with the osteoplastic material Osteomatrix (lyophilized purified bovine bone collagen matrix (Conect-biofam, Russia). The phenomena similar to those found at implantation of mineral natural osteoplastic materials were detected (Figure 6).

\section{Discussion}

The current notion about granulomatous inflammation and giant-cell infiltration is evidence that every variant of cellular reaction to this or that event in the tissues is characterized by morphofunctional specificity of the multinucleate cells involved in them $[5,8,13]$. Our observations demonstrate similar activity of multinucleate cells with different morphotype toward the osteoplastic materials of various classes. All of them show concurrently the properties and functions of osteoclasts and giant cells of foreign bodies which does not agree with their present conventional classification. The cells of osteoclastic and giant-cell phenotype participate in the process of material and bone substance resorption. The cell phenotype is most likely to depend on the material properties. Thus, deproteinized and native (without demineralization) materials of xenogenic origin and new bone tissue formed with their participation are resorbed by osteoclasoid cells while demineralized, synthetic, mineral, and polymer materials by the giant cells of foreign bodies. In future, it is essential to identify clearly the whole cell pool of the macrophagal lineage engaged in this process with the application of immunohistochemical and cytogenetic methods of investigations.

In our opinion, the reason of triggering parallelly the program of osteoclasia and resorption of the foreign body should be sought for in the plasticity of macrophagal cell genetic program realization which depends on biological, chemical, and immunological properties of the interactive object. Thus, at the early stages of osteogenesis, substantial aggregations of osteoclasts may be found in bone regenerates which are conceivably involved in the regulation of neoosteogenesis preventing the generation of the excessive bone material. Besides, functioning of this type of cells within the basic multicelled units and cytokine regulation of osteoblast activity and vice versa should not be disregarded.

When regeneration is not stimulated, osteoclasia becomes evident 3 days after the introduction of osteoplastic material into the bone wound defect. Islets of primary osteogenesis and new reticulofibrous bone tissue are surrounded with numerous osteoclasts which resorb the neoformed trabecules and phagocyte the osteocytes dropped out of the lacunes (Figure 7). So, the process of osteoclastic resorption can, under the normal conditions, be accompanied by the involvement of not only nonviable

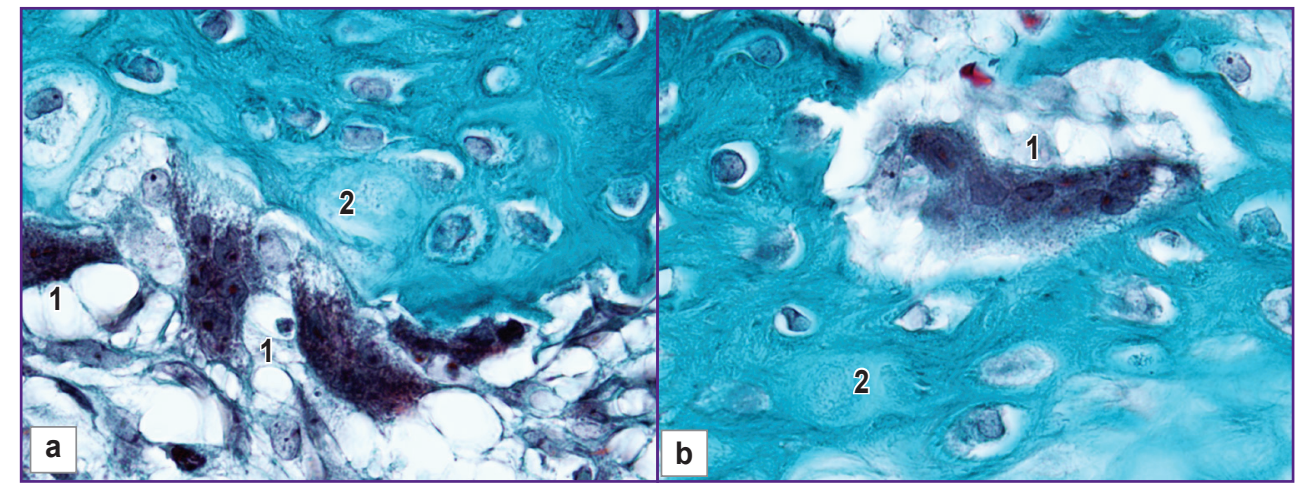

Figure 7. A histological section fragment of the adaptive subperiosteal regenerate originated on the side opposite the critical defect of the rat femoral bone surface:

(a) osteoclastic resorption of the neoformed bone as an adaptive mechanism of bone remodeling; (b) osteoclastic resorption of the neoformed bone; phagocytosis of the living osteoblasts and osteocytes; 1 - osteoclasts; 2 - a neoformed reticulofibrous bone tissue; Masson-Goldner staining; $x 1000$ 


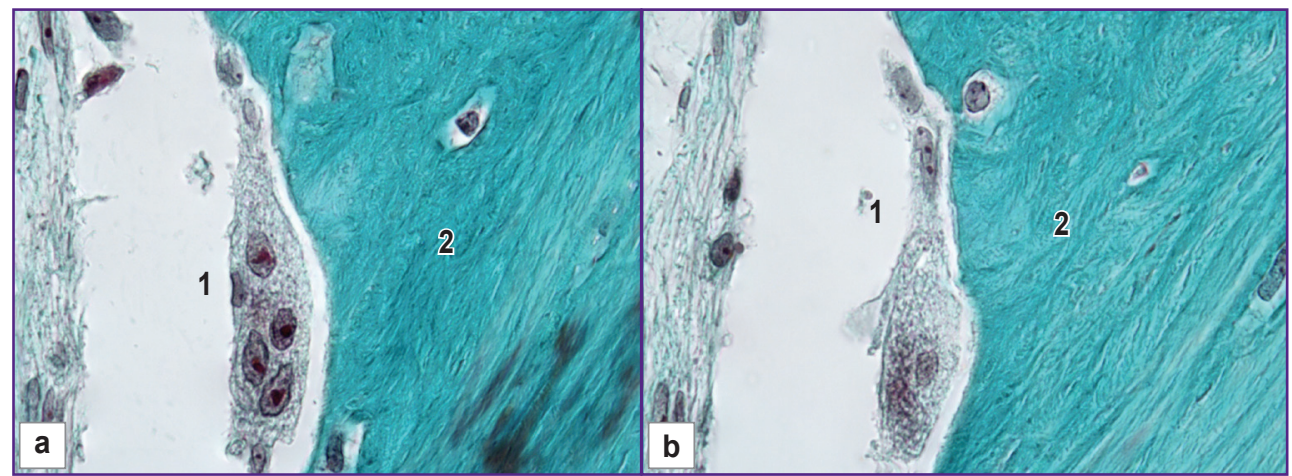

Figure 8. A fragment of the bone regenerate trepanobioptate 180 days after tooth extraction:

(a), (b) series sections; physiological osteoclastic resorption of the bone tissue does not exclude phagocytosis of the viable osteocytes; 1 - osteoclasts; 2 - a neoformed lamellar bone tissue; Masson-Goldner staining; x1000

but also absolutely normal bone tissue (Figure 8). Notably, that a similar process of osteoclastic resorption of the neoformed bone tissue is also noted during bone fracture healing including those resulted from highenergy wounding. This phenomenon is considered to develop in the second part of the reparative osteogenesis and marks a phase of functional adaptation of the bone regenerate (remodeling) to the functional load on the bone organ. The biological sense of this phenomenon at the early period after osteoplastic operations with synthetic and natural materials needs further analysis.

\section{Conclusion}

The observations presented in the article point to the existence of a peculiar phenomenon in implantology: material-associated bone resorption when hyperstimulation of osteogenesis by osteoplastic materials is accompanied by remodeling of the bone matrix in the course of reparative osteogenesis and, concurrently, by the resorption of osteoplastic material by different but functionally united cells of the macrophagal lineage. We believe that at some period of time this process acquires the signs of inversion to one or another direction which may cause excessive resorption in the material and the bone tissue.

Study funding. The investigation of poly(3hydroxybutyrate) specimens was financially supported by the Russian Ministry of Education and Science (agreement 14.607.21.0119 of 27.10.2015, identifier RFMEFI60715X0119).

Conflicts of interest. The authors have no conflicts of interest to declare.

\section{References}

1. Valentin J.E., Stewart-Akers A.M., Gilbert T.W., Badylak S.F. Macrophage participation in the degradation and remodeling of extracellular matrix scaffolds. Tissue Eng Part A 2009; 15(7): 1687-1694, https://doi.org/10.1089/ten. tea.2008.0419.

2. Detsch R., Boccaccini A.R. The role of osteoclasts in bone tissue engineering. J Tissue Eng Regen Med 2015; 9(10): 1133-1149, https://doi.org/10.1002/term.1851.

3. Volkov A.V. On the safety of osteoplastic materials. Vestnik travmatologii i ortopedii im. N.N. Priorova 2015; 1: 46-51.

4. Deev R.V., Isaev A.A., Kochiesh A.Yu., Tikhilov R.M. Cellular technologies in traumatology and orthopedics: ways of development. Geny i kletki 2007; 2(4): 18-30.

5. Badylak S.F., Valentin J.E., Ravindra A.K., McCabe G.P., Stewart-Akers A.M. Macrophage phenotype as a determinant of biologic scaffold remodeling. Tissue Eng Part A 2008; 14(11): 1835-1842, https://doi.org/10.1089/ten. tea.2007.0264.

6. Davies J.E., Matta R., Mendes V.C., Perri de Carvalho P.S. Development, characterization and clinical use of a biodegradable composite scaffold for bone engineering in oro-maxillo-facial surgery. Organogenesis 2010; 6(3): 161166, https://doi.org/10.4161/org.6.3.12392.

7. Bozo I.Ya., Deev R.V., Drobyshev A.Yu., Komlev V.S., Rozhkov S.I., Eryomin I.I., Dalgatov I.G., Volozhin G.A., Grachyov V.I., Fedotov A.Yu., Isaev A.A. Efficacy of genactivated osteoplastic material based on octacalcium phosphate and plasmid DNA containing VEGF gene for critical-sized bone defects substitution. Vestnik travmatologii i ortopedii im. N.N. Priorova 2015; 1: 35-42.

8. Brodbeck W.G., Anderson J.M. Giant cell formation and function. Curr Opin Hematol 2009; 16(1): 53-57, https://doi. org/10.1097/moh.0b013e32831ac52e.

9. Mikhailovskiy A.A., Kulakov A.A., Volkov A.V. Maintaining bone tissue volume in the alveolar ridge after symmetric augmentation of extraction sitees: clinicall and morphological study. Klinicheskaya i eksperimental'naya morfologiya 2015; 1(13): 8-18.

10. Alekseeva I.S., Rachinskaia O.A., Volkov A.V., Kulakov A.A., Gol'dshtein D.V. A comparative evaluation of bone tissue formation by tissue scaffold and osteoplastic material "Bio-Oss" transplantation in the maxillary sinus floor. Stomatologiya 2012; 91(6): 41-44.

11. Muraev A.A., Bonartsev A.P., Gazhva Yu.V., Riabova V.M., 


\section{ADVANCED RESEARCHES}

Volkov A.V., Zharkova I.I., Stamboliev I.A., Kuznetsova E.S., Zhuikov V.A., Myshkina V.L., Mahina T.K., Bonartseva G.A., Yakovlev S.G., Kudryashova K.S., Voinova V.V., Mironov A.A., Shaitan K.V., Gazhva S.I., Ivanov S.Yu. Development and preclinical studies of orthotopic bone implants based on a hybrid construction from poly(3-Hydroxybutyrate) and sodium alginate. Sovremennye tehnologii v medicine 2016; 8(4): 42-50, https:// doi.org/10.17691/stm2016.8.4.06.

12. Bonartsev A.P., Zharkova I.I., Yakovlev S.G. Myshkina V.L., Makhina T.K., Zernov A.L., Kudryashova K.S.,
Feofanov A.V., Akulina E.A., Ivanova E.V., Zhuikov V.A., Volkov A.V., Andreeva N.V., Voinova V.V., Bonartseva G.A., Shaitan K.V., Kirpichnikov M.P. Adhesion and growth of bone marrow mesenchymal stem cells on 3D scaffolds from poly(3hydroxybutyrate)-poly(ethylene glycol) copolymer. J Biomater Tissue Eng 2016; 6(1): 42-52.

13. Shekhter A.B., Rozanova I.B. Tkanevaya reaktsiya na implantat. V kn.: Biosovmestimost' [Tissue reaction to the implant. In: Biocompatibility]. Pod red. Sevast'yanova V.I. Moscow; 1999; p. 174-211. 